\title{
Walk towards sustainability: Improved neighbourhood street connectivity helps
}

\author{
Yasmeen $\mathrm{Gul}^{1 *}$, Gul Ahmed $\mathrm{Jokhio}^{2}$, and Tehmina $\mathrm{Bibi}^{3}$ \\ ${ }^{1}$ Assistant Professor, Alghurair University, Dubai, United Arab Emirates. \\ ${ }^{2}$ Assistant Professor, British University in Dubai, United Arab Emirates. \\ ${ }^{3}$ Assistant Professor, Azad Jammu and Kashmir University, Pakistan.
}

\begin{abstract}
Walking is important for human health, and street connectivity has been considered as an important attribute to enhance walking. Although street connectivity has been investigated widely in this field of study, the effects of street connectivity on walking have not been investigated with gated neighborhoods' perspective. Therefore, this study's objectives are comparing connectivity in gated and non-gated neighborhoods and investigating the association of connectivity with total walking in developing countries. Space Syntax (axial map) has been used to calculate connectivity in 16 neighborhoods, of Karachi, Pakistan. Neighborhood Physical Activity Questionnaire (NPAQ) has been used ( $\mathrm{n}=1,042$ adults) to calculate total walking. Independent sample t-test has been used to check the differences in connectivity and total walking between gated and non-gated neighborhoods, while cross-tabulation (gamma test) has been used to analyze the association. The results show that connectivity and total walking are higher in non-gated neighborhoods than gated neighborhoods, and there is a small but significant association between connectivity and total walking. It indicates that total walking may be correlated to connectivity, therefore, it should be taken into account while designing neighborhoods.
\end{abstract}

\section{Introduction}

Experts in public health emphasize that increased physical activity levels can partially abate the global burden of non-communicable diseases among the populace, a view shared and promoted by the World Health Organization (WHO) [1]. To be sufficiently physically active, one should achieve $600 \mathrm{MET} / \mathrm{week}$; one of the ways to achieve this is to do 30 minutes of brisk walking a day for five days a week. Walking can be done either for some practical purpose or for leisure and/or health benefits; the former is termed as Practical Walking while the latter is termed as Recreational Walking. Over the past couple of decades, there has been an increased focus in the scientific literature on the association between walking behavior and neighborhood built environment. There are two distinguished groups; experts in urban and transportation planning, and experts in public health literature; who are studying how a

*Corresponding author: Yasmeen.gul@agu.ac.ae 
neighborhood-built environment can enhance physical activity, especially the populace's walking behavior. There are three fundamental characteristics of a neighborhood built environment; land-use patterns, transportation, and design features; which affect physical activity and walking [2,3]. The land-use patterns consist of the land-use mix, housing density, and street connectivity $[4,5]$.

Street connectivity is defined in several different ways, for example, in some studies it is defined as the measure of direct and alternative routes available from one point within a street network to another [6]; some have counted the number of intersections per unit area [7]; some have measured the T- and 4-way intersections as a percentage [4]; some have calculated it through average block area [8]; or median block area [9]; and some have investigated it through the count of entrance and exit links [10]. Using these measures, the former research has investigated the street connectivity relationship with smaller blocks of neighborhoods [7, $11,12]$ with walking especially with the practical kind. On the other hand, walking behavior for leisure or recreational purposes has been mostly associated with the design features of neighborhoods such as streetscape (i.e. sidewalk width and its continuity, the presence of cycling/walking paths and crosswalks, street furniture, streetlights, and landscaping). There are positive associations found in the literature between the presence of sidewalks [13], the presence of footpaths [14], and accessibility to opportunity for activity [15] with recreational walking. Some studies have failed to show such relationships between recreational walking and street connectivity [16, 17].

Street connectivity can be measured using several methods, such as a street network (centerline) in GIS and Space Syntax (Axial maps/lines) to correlate it with walking [18]. A few neighborhood studies have counted the number of true intersections using the GIS street network and investigated the association with walking [19, 20]. The GIS method's limitation is that GIS database is not available and accessible in every part of the world, especially in developing countries [21]. An alternative is the Space Syntax method, which can quantify urban spaces' configurational properties [22]. It has been widely used in different studies, for example, the study of the effects of super block street patterns on walking [23] and the effects of walkability on walking [24]. These researchers agree that neighborhoods with better street connectivity, longer lines of sight, and more direct links to other neighborhoods attract people's greater movement. The strength of Space Syntax method is that it is compatible with Aerial maps, which are easily available in every part of the world. This method can be used to measure street connectivity objectively in areas where there is no GIS database (street network) available especially in developing countries.

While several researchers have investigated the correlation between walking and street connectivity, no studies have investigated the effects of a new form of neighborhoods, the gated neighborhoods (GC's), which are growing very fast all over the world $[14,15,16]$. The GC's are generally developed to serve one of the three purposes; prestigious GC's to house the upper class, lifestyle GC's to keep upper-middle class physically active, and security zone GC's $[14,17,18]$. The trend is also growing fast in developing countries, however, the GC's here are generally a combination of all of the above types [28, 29]. It is also estimated that by 2030, most of the neighborhoods in Karachi, Pakistan will be gated for security purposes [30].

The above discussion on available literature points out the importance of walking for human health and how much walking is needed for everyone to be physically active. Secondly, the features of neighborhood built environment such as street connectivity have been discussed in the light of literature, which are considered important for physical activity, but a gap has been found in literature to investigate the effects of street connectivity of a new form of neighborhood, the gated neighborhoods, which seal the neighborhoods from each other through walls and fences and are growing fast all over the world. Therefore, the objectives of this study are to investigate the difference in the street connectivity of gated and 
non-gated neighborhoods, and secondly, the association between street connectivity and total walking in developing countries.

\section{Method}

\subsection{Study Area}

The study area for this research was Karachi, the biggest metorpolitan city of Pakistan. Eight gated neighborhoods were matched with their counterpart non-gated neighborhoods to perform this cross-sectional study. The details regarding the study area and the study samples were presented elsewhere $[31,5,32]$.

\subsection{Data Collection}

\subsubsection{Space Syntax connectivity (independent Variable)}

Connectivity has been calculated utilizing the Space Syntax method [33]. This study has used Depthmap X 0.50 software to calculate the street connectivity. The street centerlines maps were imported from ArcGIS. The street center lines maps were converted into axial maps at the first stage in Depthmap X.0.50 [31]. The graph analysis has been done of the axial maps, the included choice (between-ness) has been selected. The street-level choice is a measure of street network connectivity [34]. The streets' connectivity and local integrations are visualized using a spectral color legend with red representing the highest values and blue representing the lowest. Local integration a space syntax metric that characterizes the streets as integrated or segregated [35]. The attributes summary provided three values; minimum, average, and maximum, for connectivity, integration, line length, mean depth, and node count. The average values for connectivity were selected for further investigation in this study. Sample values are given in Table 1.

Table 1. Attributes Summary (Depthmap -X 0.50

\begin{tabular}{|c|c|c|c|}
\hline \multicolumn{5}{|c|}{ Attribute Summary } \\
\hline Attribute & Minimum & Average & Maximum \\
\hline Choice & 0 & 855.72 & 118407 \\
\hline Connectivity & 0 & 4.07145 & 35 \\
\hline Integration & 0.210897 & 1.16099 & 4.42342 \\
\hline Line length & 0.0553004 & 28.2938 & 1193.27 \\
\hline Mean depth & 1 & 4.41306 & 17.2804 \\
\hline Node count & 1 & 118.92 & 548 \\
\hline
\end{tabular}

\subsubsection{Total Walking (Dependent Variable)}

To measure the total walking, which is the depended variable in this research, Neighborhood Physical Activity Questionnaire (NPAQ) was used [36]. Total walking was calculated as the sum of the two types of walking i.e. practical and recreational. The MET value for practical walking is 4 , whereas the same for recreational walking is 3.5 [37]. The questions which were asked from participants were reported elsewhere [31]. 


\section{Results and Discussion}

\subsection{Comparison of connectivity between gated and non-gated neighborhoods through Axial Map analysis}

The axial map analysis generated axial line through Depthmap X 0.50 (software) for gated and non-gated neighborhoods. The axial lines in red colors depict the more connected streets, and blue axial lines show less connected. The axial line analysis results for street connectivity show that there are more blue lines in gated neighborhoods (less connected) than non-gated, especially near the neighborhoods' external boundaries. On the other hand, the non-gated neighborhoods have more red axial lines (more connected) near peripheries/boundaries. The comparisons of street connectivity between gated and non-gated neighborhoods distinguish between the two types of neighborhoods' morphologies. More red axial lines in non-gated neighborhoods indicate that the non-gated neighborhoods have more connected streets within neighborhoods as well with the surrounding neighborhoods than gated neighborhoods. The blue axial lines near boundary walls in the maps of gated neighborhoods show the less street connectivity with the surrounding neighborhoods.

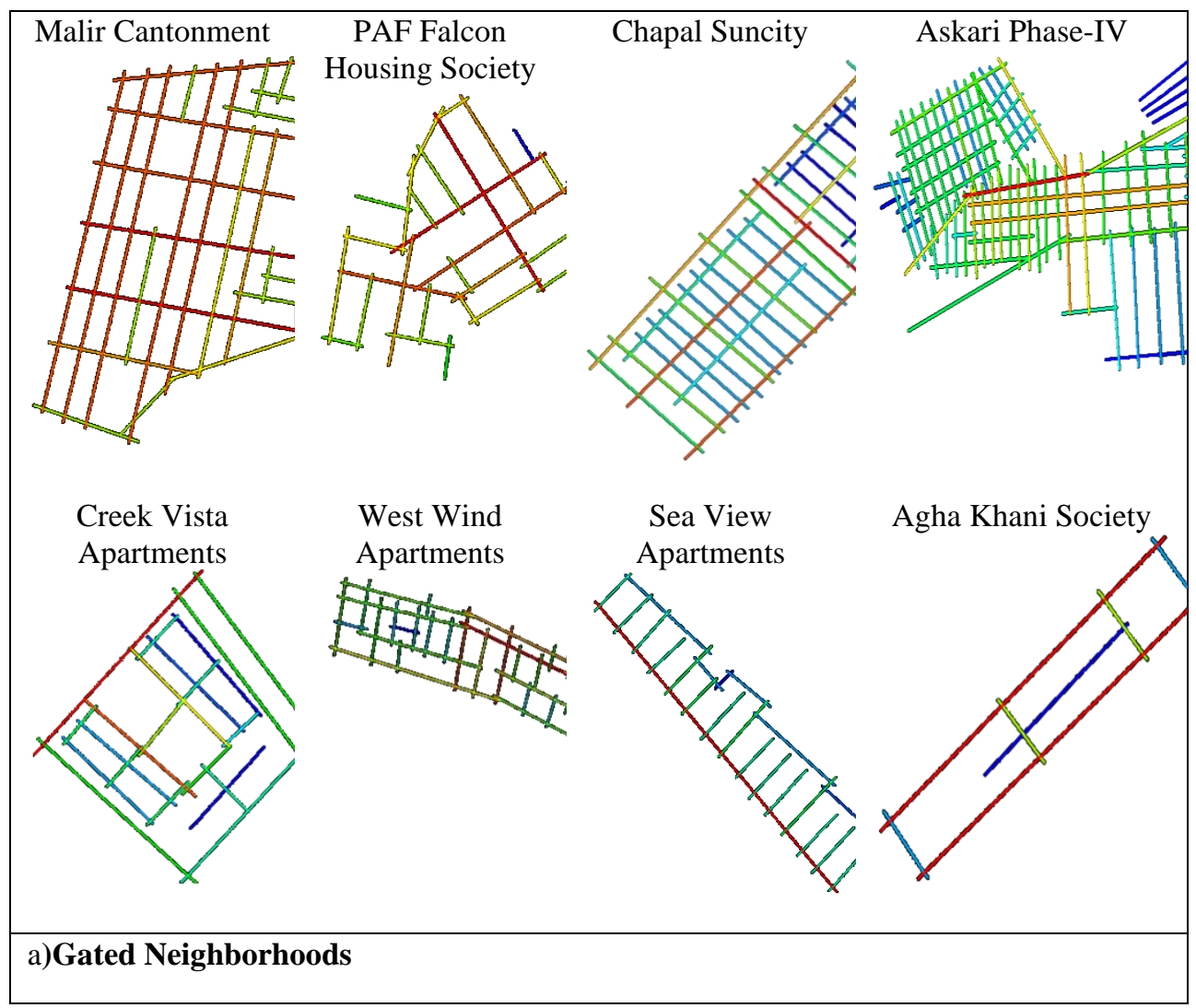



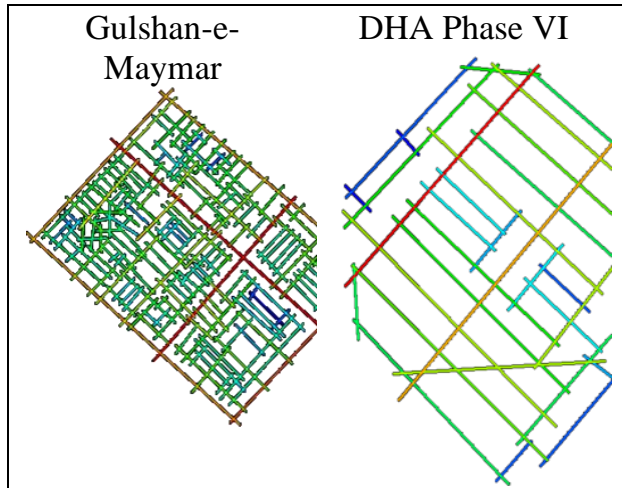

Bahadurabad Chowrangi

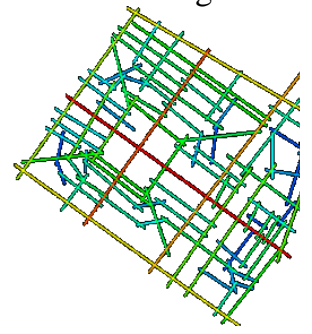

Gulistan-e-johar block-16

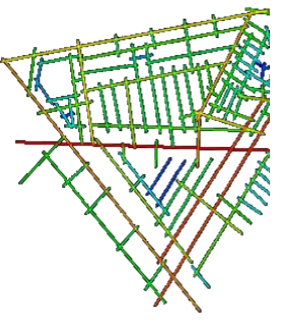

North Nazimabad Block C,D and E

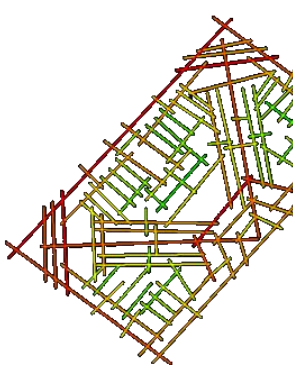

Gulshan Iqbal Block-16

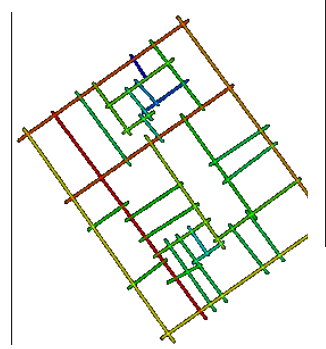

\section{Nazimabad Block-5}

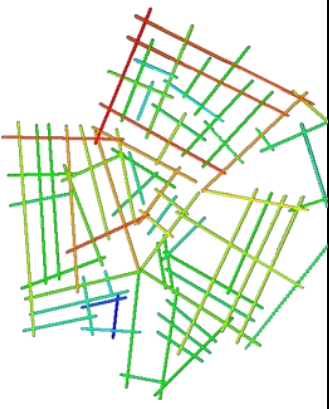

FB Area Block-3

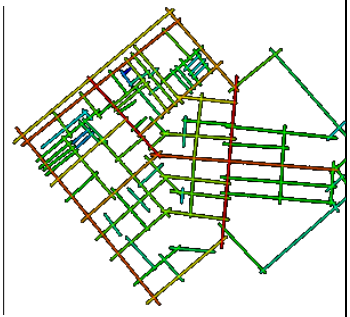

b)Non-Gated Neighborhoods

Fig. 1. Axial Map analysis a) axial maps for gated and b) for non-gated neighborhoods

This street connectivity method also provides values for choice, connectivity, integration, line length, mean depth, and nodes counts. There are three values for each attribute; minimum, average, and maximum. The average values for connectivity are then compared between gated and non-gated neighborhoods through an independent sample t-test in SPSS. The axial maps for all sixteen neighborhoods are given in Figure 1, and the values for average connectivity are given in Table 2 .

Table 2. Average Values of Connectivity through Axial Map analysis

\begin{tabular}{|c|c|c|c|c|}
\hline S.No. & Category & $\begin{array}{c}\text { Sub- } \\
\text { Categorizations }\end{array}$ & Neighbourhoods & $\begin{array}{c}\text { Average } \\
\text { Connectivity }\end{array}$ \\
\hline 1. & \multirow{6}{*}{ Gated } & \multirow[t]{4}{*}{ Single-Family } & Malir Cantonment & 4.47722 \\
\hline 2. & & & PAF-Falcon Housing Society & 4.28812 \\
\hline 3. & & & Chapal Suncity & 4.31186 \\
\hline 4 & & & Askari Phase- IV & 3.89114 \\
\hline 5. & & \multirow[t]{2}{*}{ Multi-Family } & Creek Vista Apartments & 2.15333 \\
\hline 6 & & & West Wind Apartments & 2.1 \\
\hline
\end{tabular}




\begin{tabular}{|c|c|c|c|c|}
\hline 7. & & & Sea View Apartments & 2.4436 \\
\hline 8 & & & Agha Khani Housing Society & 2.54861 \\
\hline \multicolumn{4}{|c|}{ Average for Gated } & 3.276735 \\
\hline 9 & \multirow{8}{*}{$\begin{array}{l}\text { Non- } \\
\text { Gated }\end{array}$} & \multirow[t]{4}{*}{ Single-Family } & Gulshan - e -Maymar & 3.40592 \\
\hline 10 & & & DHA Phase- VI & 4.41199 \\
\hline 11. & & & $\begin{array}{c}\text { North Nazimabad Blocks C,D } \\
\text { and E }\end{array}$ & 4.26958 \\
\hline 12. & & & Nazimabad Block-5 & 4.41284 \\
\hline 13. & & Multi-Family & Bahadarabad Chowrangi & 4.07145 \\
\hline 14. & & & Gulistan-e-Johar Block-16 & 3.87134 \\
\hline 15 & & & Gulshan -e- Iqbal Block-16 & 3.89976 \\
\hline 16 & & & FB Area Block-3 & 4.00539 \\
\hline \multicolumn{4}{|c|}{ Average for Non-gated } & 4.04353375 \\
\hline
\end{tabular}

\subsection{Comparison of connectivity and total walking (MET) between gated and non-gated neighborhoods through independent sample t-test}

An independent-samples t-test was carried out to compare street connectivity and total walking in gated and non-gated neighborhoods. There was a significant difference in connectivity values; values in gated $(\mathrm{M}=3.27, \mathrm{SD}=.95)$ and for non-gated $(\mathrm{M}=4.008$, $\mathrm{SD}=0.3)$. The conditions for connectivity values are: $\mathrm{t}(14)=-1.5, \mathrm{p}=0.0001)$. The MET values for total walking were also significantly different in gated $(\mathrm{M}=287, \mathrm{SD}=490)$ and nongated $(\mathrm{M}=353, \mathrm{SD}=674)$. The conditions for total walking MET were $\mathrm{t}(1042)=-2.0, \mathrm{p}$ (0.0001). These results suggest that connectivity and total walking MET values are significantly different in both types of neighborhoods and are more in non-gated neighborhoods than gated. The results are given in Table 3 and 4.

Table 3. Group Statistics of connectivity and total walking in gated and non-gated neighborhoods

\begin{tabular}{|c|c|c|c|c|}
\hline $\begin{array}{c}\text { Independent } \\
\text { Variables }\end{array}$ & Neighborhoods & Mean & Std. Deviation & Std. Error Mean \\
\hline Connectivity & Gated & 3.2799 & .95959 & .04296 \\
\cline { 2 - 5 } & Non-Gated & 4.0048 & .30399 & .01305 \\
\hline Total Walking & Gated & 287.1283 & 448.79204 & 20.09069 \\
\hline & Non-Gated & 353.4972 & 593.90001 & 25.48669 \\
\hline
\end{tabular}


Table 4. Independent Sample T-test showing connectivity and total walking in gated and non-gated neighborhoods

\begin{tabular}{|c|c|c|c|c|c|c|c|c|c|c|}
\hline & \multicolumn{2}{|c|}{$\begin{array}{c}\text { Levene's } \\
\text { Test for } \\
\text { Equality of } \\
\text { Variances }\end{array}$} & \multicolumn{7}{|c|}{ t-test for Equality of Means } \\
\hline & & \multirow[b]{2}{*}{$\mathrm{F}$} & \multirow[b]{2}{*}{$\begin{array}{l}\mathrm{Si} \\
\mathrm{g} .\end{array}$} & \multirow[b]{2}{*}{$\mathrm{t}$} & \multirow[b]{2}{*}{ df } & \multirow{2}{*}{$\begin{array}{l}\text { Sig. } \\
(2- \\
\text { taile } \\
\text { d) }\end{array}$} & \multirow{2}{*}{$\begin{array}{c}\text { Mean } \\
\text { Differe } \\
\text { nce }\end{array}$} & \multirow{2}{*}{$\begin{array}{c}\text { Std. } \\
\text { Error } \\
\text { Differe } \\
\text { nce }\end{array}$} & \multicolumn{2}{|c|}{$\begin{array}{c}95 \% \\
\text { Confidence } \\
\text { Interval of the } \\
\text { Difference }\end{array}$} \\
\hline & & & & & & & & & Lower & $\begin{array}{c}\text { Uppe } \\
\text { r }\end{array}$ \\
\hline \multirow[t]{2}{*}{$\begin{array}{l}\text { Connecti } \\
\text { vity }\end{array}$} & $\begin{array}{l}\text { Equal } \\
\text { varian } \\
\text { ces } \\
\text { assum } \\
\text { ed }\end{array}$ & $\begin{array}{r}3156.8 \\
24\end{array}$ & $\begin{array}{r}.00 \\
0\end{array}$ & $\begin{array}{r}1.5 \\
45\end{array}$ & 14 & .000 & -.72483 & .04337 & -.80993 & $\begin{array}{r}.6397 \\
2\end{array}$ \\
\hline & $\begin{array}{l}\text { Equal } \\
\text { varian } \\
\text { ces not } \\
\text { assum } \\
\text { ed }\end{array}$ & & & $\begin{array}{r}- \\
1.5 \\
45\end{array}$ & 12.781 & .000 & -.72483 & .04489 & -.81300 & $\begin{array}{r}- \\
.6366 \\
5\end{array}$ \\
\hline \multirow[t]{2}{*}{$\begin{array}{l}\text { Total } \\
\text { Walking }\end{array}$} & $\begin{array}{l}\text { Equal } \\
\text { varian } \\
\text { ces } \\
\text { assum } \\
\text { ed }\end{array}$ & 14.935 & .000 & $\begin{array}{r}- \\
2.0 \\
22\end{array}$ & 1040 & .043 & $\begin{array}{r}- \\
66.3689 \\
8\end{array}$ & $\begin{array}{r}32.8298 \\
7\end{array}$ & $\begin{array}{r}- \\
130.789 \\
32\end{array}$ & $\begin{array}{r}- \\
1.948 \\
64\end{array}$ \\
\hline & $\begin{array}{l}\text { Equal } \\
\text { varian } \\
\text { ces not } \\
\text { assum } \\
\text { ed }\end{array}$ & & & $\begin{array}{r}- \\
2.0 \\
45\end{array}$ & $\begin{array}{r}1003.2 \\
56\end{array}$ & .041 & $\begin{array}{r}- \\
66.3689 \\
8\end{array}$ & $\begin{array}{r}32.4531 \\
5\end{array}$ & $\begin{array}{r}- \\
130.052 \\
82\end{array}$ & $\begin{array}{r}- \\
2.685 \\
14\end{array}$ \\
\hline
\end{tabular}

\subsection{Associations between Connectivity and total walking (MET)}

For investigating the association between street connectivity and total walking, the connectivity was categorized into quartiles of very low, low, high, and very high; and the total walking MET was categorized into 0 walking, $<600$ MET, and $>600$ MET of walking in a week according to the WHO guidelines. The cross-tabulation results in Table 6 show that $29.2 \%$ of people get $>600$ MET of walking according to WHO guidelines when the connectivity is high (i.e., value-3-4). The association decreases again in the very high (i.e., values $>4$ ) of connectivity, which shows that connectivity has an effect on total walking when it is neither very low (i.e., value <3) nor very high (i.e., values $>4$ ). The connectivity encourages people to walk and get $>600$ MET minutes in a week when the average values are from 3.0-4.0. Less than three and more than four average connectivity values discourage walking at the neighborhood level. 
Table 5. Cross-Tabulation between connectivity and total walking in a week

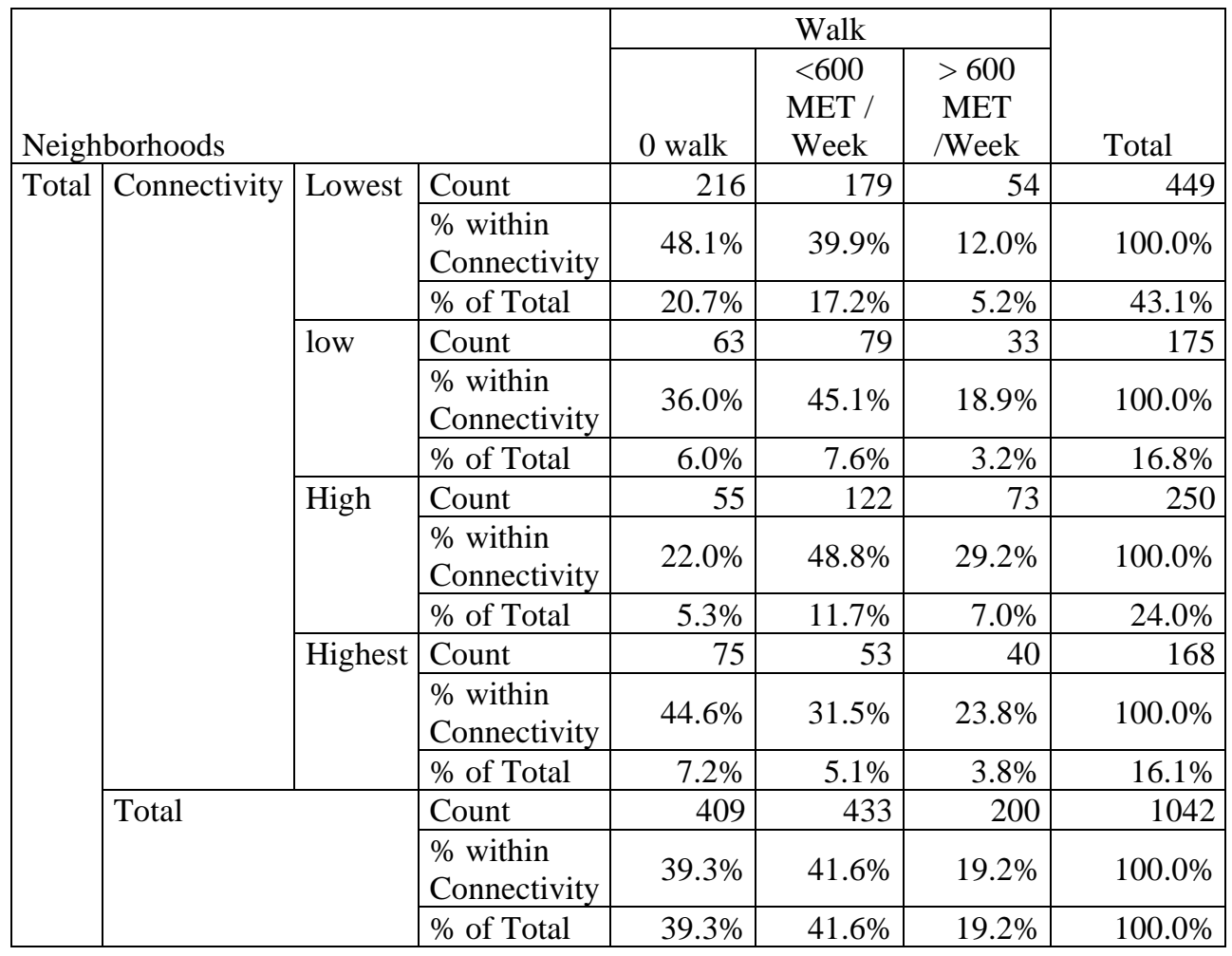

The results of gamma tests in Table 6 show that there is a significant association between connectivity and total walking with the p-value of 0.04 , which is less than 0.05 , but the value of this association is $12.1 \%$, which shows that there is small effect size. Therefore, it can be concluded that connectivity has an association with total walking when it is neither very low nor very high. It encourages walking only if it is in the range of 3-4 when calculated through Depth map-X 0.50 . The less than three connectivity probably discourages walking due to less connectivity with other streets, and more than four connectivity discourages walking probably because it encourages more commercial activities, crowded streets, and traffic. In this regard, the policy guideline can be that streets should not be sealed completely through walls such as in the gated neighborhoods, neither should there be many streets to produce crowded streets and increased traffic, which are hindrances for walking at the neighborhood level.

Table 6. Gamma test between Street connectivity and total walking in a week

\begin{tabular}{|c|c|c|c|c|c|c|c|}
\hline \multicolumn{4}{|c|}{ Neighborhoods } & Value & $\begin{array}{l}\text { Asymp. } \\
\text { Std. Error }\end{array}$ & $\begin{array}{c}\text { Approx. } \\
\mathrm{T}^{\mathrm{b}}\end{array}$ & $\begin{array}{c}\text { Approx. } \\
\text { Sig. }\end{array}$ \\
\hline \multirow[t]{3}{*}{ Total } & \multirow{2}{*}{$\begin{array}{l}\text { Ordinal by } \\
\text { Ordinal }\end{array}$} & \multirow[t]{2}{*}{ Gamma } & Zero-Order & .121 & .041 & 2.932 & .003 \\
\hline & & & $\begin{array}{l}\text { First-Order } \\
\text { Partial }\end{array}$ & .134 & & & \\
\hline & \multicolumn{3}{|c|}{$\mathrm{N}$ of Valid Cases } & 1042 & & & \\
\hline
\end{tabular}




\subsection{Discussion}

The comparison of street connectivity in gated and non-gated neighborhoods shows that Karachi's non-gated neighborhoods are better connected than their gated counterparts. Therefore, it can be suggested through this study that gated neighborhoods discourage street connectivity at the neighborhood level. This outcome agrees with the literature on gated communities, which says that these developments are segregated from surrounding neighborhoods [38, 39]. Burke and Sebaly [38] used street vitality index in their study and concluded that greater number of children play in non-gated neighborhoods of Australia. The authors also concluded that people use more vehicles for small distances outside gated neighborhoods as compared to non-gated neighborhoods. Similarly, Miao (2003) concluded that the streets in gated neighborhoods are deserted near boundary walls because of the lack of links between neighborhoods.

The second conclusion drawn from the results of this study is that there is a positive correlation between connectivity and total walking in Karachi, Pakistan, which is similar to other developed countries, and these results are consistent with the study of Baran, et al. [18]. They studied the effects of Space-Syntax-measured connectivity on walking in North Carolina. They concluded that connected streets provided direct accessibility and thus less angularity than not-connected streets, therefore, the neighborhoods that offer highly accessible streets to their residents appear to encourage more walking. These results of the association between connectivity and total walking are also in agreement with the study of Peponis et al. [23] who reported that connected streets are livelier and attract more people to walk. In summary, it can be said that connectivity has a positive association with walking in developing countries as well.

These study strengths are that connectivity through objective methods (Space Syntax) may provide valuable help to policymakers and city planners for future designing of neighborhoods for encouraging street connectivity at an appropriate level. The limitation of this study is that it is a one-time cross-sectional study, therefore, the effects of the different times of the year couldn't be reported.

\section{Conclusion}

Therefore, it can be concluded that connectivity should be there between neighborhoods for better walking. To reinforce the findings, the relationships between Space-Syntax-measured connectivity and walking should be studied in other regions.

\section{References}

[1] Transportation Research Board/Institute of Medicine, "Does the Built Environment Influence Physical Activity? Examining the Evidence,", TRB Special Report, 282, 2005 .

[2] L. D. Frank, T. L. Schmid, J. F. Sallis, J. Chapman and B. E. Saelens, "Linking Objectively Measured Physical Activity with Objectively Measured Urban Form: Findings from SMARTRAQ," American Journal of Preventive Medicine, vol. 28, no. 2, pp. 117-125, 2005.

[3] S. L. Handy, "Urban form and pedestrian choices: study of Austin neighborhoods, ,," Transportation Research Record, pp. 1552, pp. 135-144, 1996. 
[4] K. J. Krizek, " Residential relocation and change in urban travel: does neighborhoodscale urban form matter?," Journal of the American Planning Association, , pp. 69(3), pp. 265-279. , 2003.

[5] A. Forsyth, "Twin Cities Walking Study: Environment and Physical Activity:," pp. GIS Protocols, Version 4.0. Available at http://www.designcenter.umn.edu/projects/current/health/ epaGISprotocols.html, 2006.

[6] M. G. McNally and S. Ryan, "Comparative assessment of travel characteristics for neotraditional designs,", Transportation Research Record,, pp. 1400, pp. 67-77, 1993.

[7] M. J. Greenwald and M. G. Boarnet, "Built environment as determinant of walking behavior: analyzing nonwork pedestrian travel in Portland, Oregon," Transportation Research Record, pp. 1780, pp. 33-42, 2000.

[8] A. V. Moudon, C. Lee, A. D. Cheadle, C. Garvin, D. Johnson, T. L. Schmid, R. Weathers and L. Lin, "Operational definitions of walkable neighborhood: theoretical and empirical insights," Journal of Physical Activity and Health, pp. 3(Sup. 1), pp. S99-, 2006.

[9] B. Giles-Corti and R. J. Donovan, "The relative influence of individual, social and physical environment determinants of physical activity," Social Science \& Medicine,, pp. 54(12), pp. 1793-1812, 2002.

[10] B. Corti, R. J. Donovan and C. Holman, "Factors influencing the use of physical activity facilities: results from qualitative research," Health Promotion Journal of Australia, pp. 6, pp. 16-21., 1996.

[11] B. Giles-Corti, A. Timperio, F. Bull and T. Pikora, "Understanding physical activity environmental correlates: increased specificity for ecological models. Exercise and Sport Sciences Reviews," Exercise and Sport Sciences Reviews, pp. 33(4), 175e181., 2005.

[12] J. F. Sallis, M. F. Johnson, K. J. Calfas, S. Caparosa and J. F. Nichols, "Assessing perceived physical environmental variables that may influence physical activity,," Research Quarterly for Exercise and Sport,, pp. 68(4), pp. 345-351, 1997.

[13] S. Wilcox, C. Castro, A. C. King, R. A. Houseman and R. Brownson, "Determinants of leisure time physical activity in rural compared with urban older and ethnically diverse women in the United States," Journal of Epidemiology and Community Health, p. 5, 2000.

[14] E. J. Blakely and M. G. Snyder, "Divided We Fall: Gated and Walled Communities in the United States," in Architecture of Fear, N. Ellin, Ed., New York, Princeton Architectural Press, 1997.

[15] Y. Gul, Z. Sultan, M. Moeinaddini and G. A. Jokhio, "Measuring the differences of neighbourhood environment and physical activity in gated and non-gated neighbourhoods in Karachi, Pakistan," Journal of Urban Design, pp. 24 (3), 494-513, 2019. https://doi.org/10.1080/13574809.2018.1468216

[16] Y. Gul, Z. Sultan and G. A. Jokhio, "The association between the perception of crime and walking in gated and non-gated neighbourhoods of Asian developing countries," Heliyon , p. 715, 2018. https://doi.org/10.1016/j.heliyon.2018.e00715

[17] J. Grant and L. Mittelsteadt, "Types of gated communities," Environment and Planning B: Planning and Design, vol. 31, pp. 913-930, 2004.

[18] Y. Gul, Z. Sultan, M. Moeinaddini and G. A. Jokhio, "The effects of sociodemographic factors on physical activity in gated and non-gated neighbourhoods in 
Karachi, Pakistan," Sport in Society, pp. 1225-1239, 2019/7/3. https://doi.org/10.1080/17430437.2018.1508208

[19] W. Breitung, "Enclave Urbanism in China: Attitudes Towards Gated Communities in Guangzhou," Urban Geography, vol. 33, no. 2, pp. 278-294, 2012.

[20] H. Leisch, "Gated communities in Indonesia," Cities, vol. 19, no. 5, pp. 341-350, 2002.

[21] N. Ahmad, "Choice of Neighbourhoods by Mover Households in Karachi," Urban Studies, pp. 1257-1270, 1993.

[22] Y. Gul, Effects Of Neighbourhood Environment On Physical Activities In Gated And Non-Gated Neighbourhoods In Karachi, Pakistan, Johar Bahru: UTM, 2017.

[23] Y. Gul, S. Zahid and G. A. Jokhio, "Contribution to the Environmental sustainability by improving the walking behaviour through neighbourhoods' design with special reference to developing countries," E3S Web of Conferences, pp. 158, 02002, 2020. https://doi.org/10.1051/e3sconf/202015802002

[24] Y. Gul, Z. Sultan, M. Moeinaddini and G. A. Jokhio, "The effects of physical activity facilities on vigorous physical activity in gated and non-gated neighborhoods," Land use policy, pp. 155-162, 2018. https://doi.org/10.1016/j.landusepol.2018.05.040

[25] B. Giles-Cort, A. Timperio, H. Cutt, T. J. Pikora, F. C. Bull, M. Knuiman, M. Bulsara, K. V. Niel and T. Shilton, "Development of a reliable measure of walking within and outside the local neighborhood: RESIDE's Neighborhood Physical Activity Questionnaire," Preventive Medicine, pp. 455-459, 2006.

[26] B. E. Ainsworth, W. L. Haskell, M. C. Whitt, M. L. Irwin, A. M. Swartz, S. J. Strath, W. L. O'brien, D. R. Bassett, k. H. Schmitz, P. O. Emplaincourt, D. R. Jacobs and A. S. Leon, "Compendium of physical activities: an update of activity codes and MET intensities.," Medicine and Science in Sports and Exercise, pp. S498-S504, 2000.

[27] World Health Organization, "Global Recommendations on Physical Activity for Health," WHO Library Cataloguing-in-Publication Data, 2010.

[28] S. L. Handy, M. G. Boarnet, R. Ewing and R. E. Killingsworth, "How the Built Environment Affects Physical Activity Views from Urban Planning," American Journal of Preventive Medicine, pp. 64-73, 2002.

[29] P. K. Baran, D. A. Rodriguez, A. J. Khattak and A. J. Khattak, "Space Syntax and Walking in a New Urbanist and Suburban Neighbourhoods," Journal of Urban Design, vol. 13, pp. 5-28, 2008.

[30] K. Sundquist, U. Eriksson, N. Kawakamia, L. Skog and H. Ohlsson, "Neighborhood walkability, physical activity, and walking behavior: The Swedish Neighborhood and Physical Activity (SNAP) study," Social Science and Medicine, pp. 1266-1273, 2011.

[31] Eva Lesliea, "Walkability of local communities: Using geographic information systems to objectively assess relevant environmental attributes," Health and Place, pp. 111-122, 2007.

[32] M. J. Koohsari, A. T. Kaczynski, G. R. Mcormack and T. Sugiyama, "Using Space Syntax to Assess the Built Environment for Physical Activity: Applications to Research on Parks and Public Open Spaces," Leisure Sciences, pp. 206-216, 2014.

[33] B. Hillier and J. Hanson, "The Social Logic of Space," Cambridge: Cambridge UniversityPress, 1984.

[34] J. Peponis, C. Feng, D. Green, D. Haynie, S. H. Kim, Q. Sheng, A. Vialard and H. Wang, "Syntax and parametric analysis of superblock patterns John," The Journal of Space Syntax, pp. 109-141, 2015. 
[35] M. J. Koohsari, N. Owen, E. Cerin, B. Giles-Corti and T. Sugiyama, "Walkability and walking for transport: characterizing the built environment using space syntax," International Journal of Behavioral Nutrition and Physical Activity, p. 121, 2016.

[36] M. Burke and C. Sebaly, "Locking in the pedestrian? The privatised streets of gated communities," World Transport Policy \& Practice, vol. 7, no. 4, pp. 61-66, 2001.

[37] P. Miao, "Deserted Streets in a Jammed Town: The Gated Community in Chinese Cities and Its Solution," Journal of Urban Design, vol. 8, no. 1, pp. 45-66, 2003.

[38] B. H. Lida and Shinichi, "Network and Psychological Effects in Urban Movement," Network and Psychological Effects in Urban Movement, p. 475-490, 2005.

[39] C. Sarkar, C. Webster, M. Pryor, D. Tang, S. Melbourne, X. Zhang and L. Jianzheng, "Exploring associations between urban green, street design and walking: Results from the Greater London boroughs," Landscape and Urban Planning, p. (143) 112-125, 2015.

[40] B. Jiang and C. Claramunt, "Integration of Space Syntax into GIS: New Perspectives for Urban Morphology," Transactions in GIS, p. 6(3) 295-309, 2002.

[41] Y. Gul, Z. Sultan and F. Johar, "Effects of Neighborhood's Built Environment on Physical Activities in Gated Communities: A Review," International Journal Of Built Environment And Sustainability, pp. 60-69, 2016.

DOI: https://doi.org/10.11113/ijbes.v3.n1.112 